Article

\title{
How COVID-19 Pandemic Affected Urban Trips? Structural Interpretive Model of Online Shopping and Passengers Trips during the Pandemic
}

\author{
Mostafa Ghodsi $\left.{ }^{1}{ }^{(}\right)$, Ali Ardestani ${ }^{2}{ }^{-}$, Arash Rasaizadi ${ }^{1}\left(\mathbb{C}\right.$, Seyednaser Ghadamgahi ${ }^{3}$ and Hao Yang ${ }^{2, *}$ \\ 1 Department of Transportation Engineering, Faculty of Civil and Environmental Engineering, Tarbiat Modares \\ University, Tehran 14896-84511, Iran; mostafa.ghodsi@modares.ac.ir (M.G.); \\ arash_rasaizadi@modares.ac.ir (A.R.) \\ 2 Civil Engineering Department, McMaster University, Hamilton, ON L8S 4L8, Canada; ardestaa@mcmaster.ca \\ 3 Department of Tourism Management, Allame Tabataba'i University, Tehran 14896-84511, Iran; \\ sn.ghadamgahi@gmail.com \\ * Correspondence: yangh149@mcmaster.ca
}

\section{check for} updates

Citation: Ghodsi, M.; Ardestani, A.; Rasaizadi, A.; Ghadamgahi, S.; Yang, H. How COVID-19 Pandemic Affected Urban Trips? Structural Interpretive Model of Online Shopping and Passengers Trips during the Pandemic. Sustainability 2021, 13, 11995. https://doi.org/ $10.3390 /$ su132111995

Academic Editors: Armando Cartenì, Ilaria Henke and Marc A. Rosen

Received: 9 September 2021

Accepted: 26 October 2021

Published: 29 October 2021

Publisher's Note: MDPI stays neutral with regard to jurisdictional claims in published maps and institutional affiliations.

Copyright: (C) 2021 by the authors. Licensee MDPI, Basel, Switzerland. This article is an open access article distributed under the terms and conditions of the Creative Commons Attribution (CC BY) license (https:// creativecommons.org/licenses/by/ $4.0 /)$.

\begin{abstract}
Changing people's shopping behavior from face-to-face to online shopping during the COVID-19 pandemic led to reduced shopping trips, and this decrease directly affects traffic congestion and air pollution. Identifying the factors influencing the increase of online shopping behavior during the pandemic can be helpful for policymakers in the post-COVID-19 era. This study aims to discover the effect of factors related to the COVID-19 pandemic and demographic characteristics on shopping attitude and, consequently, on shopping trips. Based on the interviews of ten experts, factors associated with COVID-19 and demographic characteristics are selected as influential factors on shopping attitude and shopping trips. For pairwise comparisons between these factors, a web-based questionnaire was designed and given to thirty experts. The relationship between all factors is examined using interpretive structural modeling (ISM) and Microscopic-Macroscopic (MICMAC) analysis. In addition, to prioritize factors, the IAHP model is employed. Based on the results, five levels of influential factors affect shopping attitude, which affects shopping trips: level 1, age and gender; level 2, income and education; level 3, the household size and the COVID-19 awareness; level 4, COVID-19 attitude and COVID-19 practice; and level 5, norm subject and shopping personal control.
\end{abstract}

Keywords: online shopping; urban traffic; urban travel demand; COVID-19 pandemic

\section{Introduction}

The amount of online shopping increased to an unprecedented level during the COVID-19 epidemic. Several factors such as general fear of COVID-19, quarantine rules, and health recommendations altered the activity patterns of people [1]. One of the most fundamental manifestations of this change was in people's shopping behavior, which changed from physical to online [2]. A review of the pandemic impact on retail e-commerce shows unusual global traffic growth, and the number of visits to retail websites increased from 16.07 billion worldwide in January 2020 [3]. However, these changes were influenced by various factors, and understanding the position of each of these variables in relation to online shopping and city travel during the pandemic could influence the decisions of industry owners as well as governments in similar crises.

COVID-19's readiness strategies directly affected retail store customer satisfaction, including sanitized retail entryways, sanitized retail shelves, and sanitized retail counters [4]. The perceived sense of safety against the COVID-19 virus during shopping became one of the essential attitudes of customers, and since all the retail enterprises did not adopt protective measures seriously, online shopping gained much popularity [5]. It is observed 
that people followed certain behaviors such as decreasing outside eating; increasing cooking at home [6]; and multiplying online food, fresh fruit, and vegetable shopping [6-9] to prevent disease; moreover, they were typically less willing to shop in the grocery stores physically [8]. Therefore, the pandemic caused some businesses to struggle and several online businesses to thrive such as online entertainment, food delivery, online shopping, and online education [10]. Besides the growth of online shopping, other kinds of shopping with no physical interaction, including curbside pick-up and robotic delivery, gained popularity [11].

Not only retailers experienced unpredictability during the COVID-19 pandemic [12]. The literature review reveals that $60 \%$ of residential communities had difficulties getting their essentials during lockdowns [13]. Moreover, aged people and those with a physical disability experienced numerous barriers to buying their essentials and were the most affected in the panic buying chaos [14,15]. A group of researchers tried to unravel the social media effect on the consumers' panic that led to stockpiling [16-19]. To provide managerial insights for policy-makers during such crises, analyzing the panic buying behaviors of customers seems inevitable [20,21], and "attitude", "subjective norm", and the "fear of future unavailability" were found to be the main drivers of hoarding behaviors [22].

The social distancing regulations by governments and the self-isolation decisions made by people had consequences on daily travel patterns [23-25], and the incurred changes in travel behavior due to the COVID-19 pandemic is a worthy issue [26,27]. Although the lockdown was temporary and now is ended in almost all territories, and even public transport has resumed its operation [28,29], people are trying to diminish the number of their nonwork-related trips, including (1) grocery shopping, (2) other types of shopping, (3) eating out, and (4) leisure [30]. Online shopping has reduced short-distance traffic and significantly diminished the need for parking slots at shopping centers [31]. Peng did a study in 2019 about the impact of e-commerce on traffic congestion and found a 1.4\% reduction in traffic congestion due to an increase in online shopping by $10 \%$ [32]. A group of researchers considered ten significant variables on travel behavior changes due to COVID19: (1) essential sociodemographic characteristics, (2) vehicle ownership, (3) level of social anxiety, (4) risk perception, (5) weekly trip frequency by purpose before the pandemic, (6) weekly trip frequency by purpose after the pandemic, (7) behavioral changes in response to COVID-19, (8) the degree of going-out self-restriction, (9) social expectations of going-out self-restriction behavior, (10) subjective well-being as self-restrictive behavior [30].

\section{Theoretical Background}

Ajzen developed the planned behavior theory in 1991 to predict and explain various human behaviors in specific settings and deal with arbitrary complexities of social behavior. According to the planned behavior theory, three independent variables determine intention. Firstly, an attitude refers to a person's value judgment, which indicates to what extent he or she finds the behavior favorable or unfavorable. Another predictor is a social factor called the subjective norm; it refers to the pressure people exert on an individual to follow the behavior. The third antecedent of intention is the degree to which a behavior is perceived as being controlled. This reflects one's personal experience with the task and expectations regarding impediments and obstacles that could cause a violation of the norm. According to the theory of planned behavior, trying to accomplish a behavior is a joint function of intentions and perceived behavioral control [33]. Later, Chandrea et al. analyzed the factors that affect consumers' shopping behavior as a vital issue of the ecommerce and marketing field. As independent variables, they considered demographics, desired consequences, attitude toward online shopping, subjective norms, and perceived behavior of the consumer as influences on online shopping behavior [34]. More recently, Alahdal et al. conducted a cross-sectional survey to assess the awareness, attitude, and practice of COVID-19 that concerns socioeconomic data among Riyadh residents. Several sociodemographic characteristics found in the population were considered independent variables, such as gender, age, education level, marital status, family size, and income. The 
levels of awareness, attitude, and behavior were considered as dependent variables. A score of one was given to every correct response and a score of zero for both wrong and "I'm not sure" responses. Scores ranged from 0 to 22,0 to 9 , and 0 to 11 for the level of awareness, attitude, and practice, respectively [35].

In this study, the relationship between urban trips and the shopping attitude during the pandemic is investigated. In addition, it is necessary to investigate the factors associated with shopping attitudes. These factors include factors related to the COVID-19 and demographic factors. Finally, the priority and relationship between passenger trips, shopping attitude, and COVID-19 and demographic factors are examined by using the ISM and IAHP.

The ISM approach identifies the variables related to the passenger trip and online shopping attitude. Afterward, the subordinate relation is selected for its relevance to the context. Once the contextual relation is determined, the structural self-interaction matrix (SSIM) is developed based on pairwise comparisons between variables. A reachability matrix (RM) is then constructed from the SSIM product, and transitivity is then checked. Using a matrix model, a transitivity embedding is completed. A structural model is then synthesized by partitioning the elements and extracting the ISM [36]. The following are the phases to implement ISM: (1) identify the ISM objectives to accomplish, (2) distinguish between attributes, (3) determine the relationships between the attributes, (4) develop SSIM matrix (structural self-interaction matrix), (5) convert SSIM into the initial reachability matrix (IRM), (6) compute final reachability matrix (FRM) and partition reachability matrix (RM), (7) develop canonical matrix, (8) develop pictorial view, and (9) examine the developed ISM [37].

Finally, the ISM model shows how the relationship between the considered variables and makes it possible to describe this relationship and set better policies to manage travel demand.

In the second step, to explore the priority between passenger trips, shopping attitude, and COVID-19 and demographic factors, IAHP was used. This approach is favored for its simplicity and conformity to the nine-scale principle, widely used regardless of the inconsistencies in the comparison matrix associated with classical AHPs.

The IAHP method has the following advantages over simple AHP: (1) Compatibility in comparisons: This method, with the sorting mode it creates for the criteria, forms an always consistent matrix. Simulation studies of this method show that when the number of criteria increases, the weight obtained with this method is in line with the conventional AHP method. (2) Efficiency of information extraction: Since the IAHP does not require decision makers to perform the pairwise comparison process, much effort can be saved. (3) Convenience in practice: In this method, pairwise comparisons are no longer made, so the ease of filling in comparisons leads to better and more accurate results [38].

In general, the main contribution of this study is to discover the relationship between passenger trips and shopping attitudes at the time of the COVID-19 pandemic. As summarized in Table 1, previous studies have focused on this relationship in normal conditions, but in the pandemic, this relationship is different, and this difference is caused by factors related to the COVID-19. Finally, for this purpose, the ISM and IAHP as advanced AHP have been employed. 
Table 1. Summary of related previous studies.

\begin{tabular}{|c|c|c|c|}
\hline Literature & $\begin{array}{c}\text { Data } \\
\text { (No. of Questionnaire) }\end{array}$ & Study & Methodology \\
\hline Parady et al. 2020 [30] & 800 & travel behavior change & binary logit model \\
\hline Islam et al. 2021 [20] & 1081 & panic buying & structural equation modeling \\
\hline Lins et al. 2020 [39] & 393 & panic buying & factor analysis \\
\hline Lopes et al. 2020 [17] & 411 & compulsive buying & structural equation modeling \\
\hline Passavanti et al. 2021 [40] & 1612 & psychological impact of COVID-19 & ANOVA model \\
\hline Rukuni et al. 2020 [4] & 344 & shopping behavior & structural equation modeling \\
\hline Laato et al. 2020 [16] & 211 & shopping behavior & structural equation modeling \\
\hline Grashuis et al. 2020 [9] & 900 & grocery shopping behavior & multinomial logit \\
\hline Untaru et al. [5] & 401 & physical shopping satisfactory & structural equation modeling \\
\hline Hao et al. 2020 [13] & 540 & online shopping behavior & probit model \\
\hline Gao et al. 2020 [8] & 770 & online food shopping & linear regression \\
\hline Alaimo et al. 2020 [41] & 248 & online food shopping & logit model \\
\hline Koch et al. 2020 [42] & 451 & online shopping motives & structural equation modeling \\
\hline Pencarelly et al. 2021 [2] & 937 & e-shopping behavior & $\begin{array}{c}\text { basic statistical tests } \\
\text { (Correlation, } \mathrm{U} \text { test, } \mathrm{H} \text { test) }\end{array}$ \\
\hline
\end{tabular}

\section{Data and Methodology}

\subsection{ISM Modeling}

An interactive learning model such as this results in a comprehensive learning process. A set of different elements is structured directly and indirectly in a systematic, comprehensive model. Interpretive structural modeling (ISM) identifies relationships between all factors contributing to a complex problem and ultimately represents them in a graphical structure.

Every complex problem is related to several factors in different ways. Some criteria are directly or indirectly relevant to the relevance of the COVID-19 outbreak and its impact on online shopping and urban travel. In this study, the ISM method has been applied to reveal the relationships between them, resulting in a collective insight into the issue.

A qualitative method was used to identify the parameters setting the study area (online shopping and city trips during the COVID-19 pandemic). In this method, in-depth interviews were conducted with ten experts in the field of marketing and transportation engineering. At the end of the interviews, their text was implemented and coded by two people. Each encoder was agreed upon by both coders, and in the event of a disagreement between the two coders, a third coder would give the final opinion. For more enrichment, recent articles related to this field were reviewed (when the COVID-19 disease had spread). The results of these codings were categorized, and finally, nine factors affecting shopping attitude and passenger trip were identified, which can be seen in Table 2 along with their definition.

The second stage of the study involved a web-based questionnaire designed and given to thirty experts in city management, transportation, and sociology, who gave four marks $(\mathrm{V}, \mathrm{A}, \mathrm{X}$, or $\mathrm{O})$. In the matrix of pairwise comparisons, specification types of relationships between the variables are as follows:

$V$ : element $i$ influencing element $j$.

A: element $j$ influencing element $i$.

$X$ : elements $i$ and $j$ influencing each other.

$O$ : elements $i$ and $j$ are not associated.

In Table 3, each element of the matrix is selected with the most frequency by thirty experts. 
Table 2. Definition of selected factors by experts.

\begin{tabular}{|c|c|c|}
\hline SI. NO & Factor's Name & Definition \\
\hline F1 & Shopping Attitude & $\begin{array}{l}\text { An evaluation about online shopping that consists of behavioral beliefs and } \\
\text { evaluation of behavioral outcomes }\end{array}$ \\
\hline F2 & Norm Subject & $\begin{array}{c}\text { Perceived social pressure by the individual refers to whether or not the target } \\
\text { behavior is performed }\end{array}$ \\
\hline F3 & Shopping Personal Control & $\begin{array}{c}\text { The degree that a person feels like doing or not doing a behavior that is within } \\
\text { his or her control }\end{array}$ \\
\hline F4 & COVID-19 Awareness & $\begin{array}{l}\text { Knowledge of transmission methods, symptoms, vulnerable people, } \\
\text { incubation and recovery periods, possible treatments, and virus mortality rate }\end{array}$ \\
\hline F5 & COVID-19 Attitude & $\begin{array}{l}\text { Satisfaction with the application of various restrictions such as travel, } \\
\text { community, and the application of health protocols }\end{array}$ \\
\hline F6 & COVID-19 Practice & $\begin{array}{l}\text { How to behave and how to act according to health protocols such as } \\
\text { quarantine, wearing a mask, hand washing }\end{array}$ \\
\hline F7 & Education & Level of education \\
\hline F8 & Income & Level of income \\
\hline F9 & Age & Age of a person \\
\hline F10 & Gender & The male or female sex \\
\hline F11 & Family Size & Number of individuals in the household \\
\hline F12 & Passenger Trip & Number of urban trips \\
\hline
\end{tabular}

Table 3. Marks with the most frequency of selection by thirty experts.

\begin{tabular}{|c|c|c|c|c|c|c|c|c|c|c|c|c|}
\hline & F1 & F2 & F3 & F4 & F5 & F6 & F7 & F8 & F9 & F10 & F11 & F12 \\
\hline F1 & 1 & A & $\mathrm{A}$ & $\mathrm{A}$ & $\mathrm{A}$ & A & A & A & $\mathrm{A}$ & $\mathrm{O}$ & A & $\mathrm{V}$ \\
\hline $\mathrm{F} 2$ & & 1 & $X$ & $\mathrm{~A}$ & A & A & A & A & $\mathrm{A}$ & A & $\mathrm{O}$ & $\mathrm{V}$ \\
\hline F3 & & & 1 & $\mathrm{~A}$ & $\mathrm{~A}$ & $\mathrm{~A}$ & $\mathrm{~A}$ & $\mathrm{~A}$ & $\mathrm{~A}$ & $\mathrm{O}$ & $\mathrm{O}$ & $\mathrm{V}$ \\
\hline $\mathrm{F} 4$ & & & & 1 & $\mathrm{~V}$ & $\mathrm{~V}$ & $\mathrm{~A}$ & $\mathrm{O}$ & $\mathrm{O}$ & $\mathrm{O}$ & $\mathrm{O}$ & $\mathrm{V}$ \\
\hline F5 & & & & & 1 & $\mathrm{~V}$ & A & A & $\mathrm{A}$ & $\mathrm{O}$ & A & $\mathrm{V}$ \\
\hline F6 & & & & & & 1 & A & $\mathrm{A}$ & $\mathrm{A}$ & $\mathrm{O}$ & A & $\mathrm{V}$ \\
\hline F7 & & & & & & & 1 & $X$ & $\mathrm{~A}$ & A & $\mathrm{O}$ & $\mathrm{O}$ \\
\hline F8 & & & & & & & & 1 & $\mathrm{~A}$ & A & $\mathrm{O}$ & $\mathrm{V}$ \\
\hline F9 & & & & & & & & & 1 & $\mathrm{O}$ & $\mathrm{V}$ & $\mathrm{V}$ \\
\hline F10 & & & & & & & & & & 1 & $\mathrm{O}$ & $\mathrm{V}$ \\
\hline F11 & & & & & & & & & & & 1 & $\mathrm{~V}$ \\
\hline F12 & & & & & & & & & & & & 1 \\
\hline
\end{tabular}

The availability matrix was formed by substituting four symbols $\mathrm{V}, \mathrm{A}, \mathrm{X}$, or O for one or zero according to the following principles:

V symbol converts the particular $(i, j)$ entry by " 1 " and $(j, i)$ entry by " 0 ". A symbol converts the particular $(i, j)$ entry by " 0 " and $(j, i)$ entry by " 1 ". $X$ symbol converts the particular $(i, j)$ entry by " 1 " and $(j, i)$ entry by " 1 ". symbol converts the particular $(i, j)$ entry by " 0 " and $(j, i)$ entry by " 0 ".

If the criterion $a$ affects criterion $b$ and the criterion $b$ affects criterion $c$, then the criterion $a$ must also affect the criterion $c$.

\subsection{MICMAC Analysis}

MICMAC analysis is a process for graphical representation of variables based on their influence and dependence on each other in interpretive structural modeling. Based on the power of dependence and the influence of variables, a coordinate system can be decomposed into four equal parts. This type of analysis focuses on each variable's influence and level of dependency and can be further examined to find out the range of influence.

\subsection{IAHP Modeling}

There are various ways to prioritize factors that involve pairwise comparisons, which are also known as the Analytical Hierarchy Process (AHP). The AHP seeks to select the 
most appropriate option for a given set of requirements using pairwise comparisons. This technique is also used to assess criteria.

Based on the analysis of the ISM model, the variables are arranged into five levels. The first level represents the goal, and the criteria in other levels affect the number of urban trips. The AHP model allows for only the weight of the related criteria to be considered. Thus, the AHP model is based on a goal-criteria structure, which has been used in the present study.

\section{Results}

\subsection{ISM Modeling}

Many methods were used to merge the opinions of experts, and the majority opinion was selected as the final opinion and is presented in Table 4.

Table 4. The majority opinion as the final opinion.

\begin{tabular}{|c|c|c|c|c|c|c|c|c|c|c|c|c|}
\hline & F1 & F2 & F3 & F4 & F5 & F6 & F7 & F8 & F9 & F10 & F11 & F12 \\
\hline $\mathrm{F} 1$ & 1 & 0 & 0 & 0 & 0 & 0 & 0 & 0 & 0 & 0 & 0 & 1 \\
\hline F2 & 1 & 1 & 1 & 0 & 0 & 0 & 0 & 0 & 0 & 0 & 0 & 1 \\
\hline F3 & 1 & 1 & 1 & 0 & 0 & 0 & 0 & 0 & 0 & 0 & 0 & 1 \\
\hline $\mathrm{F} 4$ & 1 & 1 & 1 & 1 & 1 & 1 & 0 & 0 & 0 & 0 & 0 & 1 \\
\hline F5 & 1 & 1 & 1 & 0 & 1 & 1 & 0 & 0 & 0 & 0 & 0 & 1 \\
\hline F6 & 1 & 1 & 1 & 0 & 0 & 1 & 0 & 0 & 0 & 0 & 0 & 1 \\
\hline F7 & 1 & 1 & 1 & 1 & 1 & 1 & 1 & 1 & 0 & 0 & 0 & 1 \\
\hline F8 & 1 & 1 & 1 & 1 & 1 & 1 & 1 & 1 & 0 & 0 & 0 & 1 \\
\hline F9 & 1 & 1 & 1 & 1 & 1 & 1 & 1 & 1 & 1 & 0 & 1 & 1 \\
\hline F10 & 1 & 1 & 1 & 1 & 1 & 1 & 1 & 1 & 0 & 1 & 0 & 1 \\
\hline F11 & 1 & 1 & 1 & 0 & 1 & 1 & 0 & 0 & 0 & 0 & 1 & 1 \\
\hline F12 & 0 & 0 & 0 & 0 & 0 & 0 & 0 & 0 & 0 & 0 & 0 & 1 \\
\hline
\end{tabular}

As can be seen in Figure 1, each criterion's input (prerequisite) and output (outcome) criteria were calculated in the subsequent step, and then common factors were determined. After removing the detected variable(s) with highest impact from the table, the operation was repeated with the remaining criteria. This step was repeated until all of the variables became hierarchized.

The final step consisted of creating and mapping a network of relationships based on the criteria of ISM and their relationships between them. It should be noted that the above steps have been implemented in the R software using the ISM package. Figure 2 shows the final output of ISM.

In Figure 2, it can be seen that other factors affect urban travel the most. At the three levels, all demographic factors in terms of age, sex, education, income, and household size have a more significant and more intrinsic influence on the other factors. COVID-19 knowledge and attitude are affected by these variables. The practice of COVID-19 health protocols will be affected by these factors, according to the identified model. The factors above affect the norm subject, the shopping attitude, and shopping personal control at a higher level than all these factors. Based on the ISM method, urban travel has the highest impact and is influenced by all the factors mentioned. The findings indicate that the COVID-19 pandemic increases online shopping and increases urban travel. 


\begin{tabular}{|c|c|c|c|c|}
\hline Variable_Names & Reachability_Set & Antecedents_Set & Intersection_Set & Level \\
\hline $\mathrm{F} 1$ & F1F12 & F1 F2 F3 F4 F5 F6 F7 F8 F9 F10F11 & $F 1$ & 0 \\
\hline $\mathrm{F} 2$ & $F 1 F 2 F 3 F 12$ & F2 F3 F4 F5 F6 F7 F8 F9 F10 F11 & $\mathrm{F} 2 \mathrm{~F} 3$ & 0 \\
\hline F3 & F1 F2 F3F12 & F2 F3 F4 F5 F6F7 F8 F9F10 F11 & $\mathrm{F} 2 \mathrm{~F} 3$ & 0 \\
\hline $\mathrm{F} 4$ & F1 F2 F3 F4 F5 F6 F12 & F4F7F8F9F10 & F4 & 0 \\
\hline F5 & F1F2 F3F5 F6 F12 & F4 F5F7F8F9F10F11 & F5 & 0 \\
\hline F6 & F1 F2 F3F6F12 & F4 F5 F6 F7 F8 F9 F10 F11 & $\mathrm{F} 6$ & 0 \\
\hline F7 & $F 1 F 2 F 3 F 4 F 5 F 6 F 7 F 8 F 12$ & F7 F8F9F10 & F7F8 & 0 \\
\hline F8 & $F 1 F 2$ F3 F4F5 F6 F7F8 F12 & F7F8F9F10 & F7F8 & 0 \\
\hline F9 & F1 F2 F3 F4 F5 F6F7 F8 F9 F11 F12 & F9 & F9 & 0 \\
\hline F10 & F1F2 F3 F4 F5 F6 F7 F8 F10F12 & F10 & F10 & 0 \\
\hline F11 & F1F2 F3F5 F6F11F12 & F9F11 & F11 & 0 \\
\hline F12 & F12 & $F 1 F 2 F 3$ F4 F5 F6F7 F8F9F10F11F12 & F12 & 1 \\
\hline
\end{tabular}

\begin{tabular}{|c|c|c|c|c|}
\hline Variable_Names & Reachability_Set & Antecedent__Set & Intersection_Set & Level \\
\hline$F 1$ & $F 1$ & $F 1 F 2 F 3 F 4 F 5 F 6 F 7 F 8 F F 10 F 11$ & $F 1$ & 1 \\
\hline$F 2$ & $F 1 F 2 F 3$ & $F 2 F 3 F 4 F 5 F 6 F 7 F 8 F 9 F 10 F 11$ & $F 2 F 3$ & 0 \\
\hline$F 3$ & $F 1 F 2 F 3$ & $F 2 F 3 F 4 F 5 F 6 F 7 F 8 F F 10 F 11$ & $F 2 F 3$ & 0 \\
\hline$F 4$ & $F 1 F 2 F 3 F 4 F 5 F 6$ & $F 4 F 7 F 8 F 9 F 10$ & $F 4$ & 0 \\
\hline$F 5$ & $F 1 F 2 F 3 F 5 F 6$ & $F 4 F 5 F 7 F 8 F 9 F 10 F 11$ & $F 5$ & 0 \\
\hline$F 6$ & $F 1 F 2 F 3 F 6$ & $F 4 F 5 F 6 F 7 F 8 F 9 F 10 F 11$ & $F 6$ & 0 \\
\hline$F 7$ & $F 1 F 2 F 3 F 4 F 5 F 6 F 7 F 8$ & $F 7 F 8 F 9 F 10$ & $F 7 F 8$ & 0 \\
\hline$F 8$ & $F 1 F 2 F 3 F 4 F 5 F 6 F 7 F 8$ & $F 7 F 8 F 910$ & $F 7 F 8$ & 0 \\
\hline$F 9$ & $F 1 F 2 F 3 F 4 F 5 F 6 F 7 F 8 F 9 F 11$ & $F 9$ & $F 9$ & 0 \\
\hline$F 10$ & $F 1 F 2 F 3 F 4 F 5 F 67 F F F 10$ & $F 10$ & $F 10$ & 0 \\
\hline$F 11$ & $F 1 F 2 F 3 F 5 F 6 F 11$ & $F 9 F 11$ & $F 11$ & 0 \\
\hline
\end{tabular}

\begin{tabular}{|c|c|c|c|c|}
\hline Variable_Names & Reachability_Set & Antecedents_Set & Intersection_Set & Level \\
\hline$F 2$ & $F 2 F 3$ & $F 2 F 3 F 4 F 5 F 6 F 7 F 8 F 9 F 10 F 11$ & $F 2 F 3$ & 1 \\
\hline$F 3$ & $F 2 F 3$ & $F 2 F 3 F 4 F 5 F 6 F 7 F 8 F F F 10 F 11$ & $F 2 F 3$ & 1 \\
\hline$F 4$ & $F 2 F 3 F 4 F 5 F 6$ & $F 4 F 7 F 8 F F F 10$ & $F 4$ & 0 \\
\hline$F 5$ & $F 2 F 3 F 5 F 6$ & $F 4 F 5 F 7 F 8 F 9 F 10 F 11$ & $F 5$ & 0 \\
\hline$F 6$ & $F 2 F 3 F 6$ & $F 4 F F 6 F 7 F 8 F 910 F 11$ & $F 6$ & 0 \\
\hline$F 7$ & $F 2 F 3 F 4 F 5 F 6 F 7 F 8$ & $F 7 F 8 F 9 F 10$ & $F 7 F 8$ & 0 \\
\hline$F 8$ & $F 2 F 3 F 4 F 5 F 6 F 7 F 8$ & $F 7 F 8 F 9 F 10$ & $F 7 F 8$ & 0 \\
\hline$F 9$ & $F 2 F 3 F 4 F 5 F 6 F 7 F 8 F 9 F 11$ & $F 9$ & $F 9$ & 0 \\
\hline$F 10$ & $F 2 F 3 F 4 F 5 F 67 F 8 F 10$ & $F 10$ & $F 10$ & 0 \\
\hline$F 11$ & $F 2 F 3 F 5 F 6 F 11$ & $F 9 F 11$ & $F 11$ & 0 \\
\hline
\end{tabular}

\begin{tabular}{|c|c|c|c|c|}
\hline Variable_Names & Reachability_Set & Antecedents_Set & Intersection_Set & Level \\
\hline F4 & F4F5F6 & F4F7F8F9F10 & F4 & 0 \\
\hline F5 & F5F6 & F4F5F7F8F9F10F11 & F5 & 0 \\
\hline F6 & F6 & F4F5F6F7F8F9F10F11 & F6 & 1 \\
\hline F7 & F4F5F6F7F8 & F7F8F9F10 & F7F8 & 0 \\
\hline F8 & F4F5F6F7F8 & F7F8F9F10 & F7F8 & 0 \\
\hline F9 & F4F5F6F7F8F9F11 & F9 & F9 & 0 \\
\hline F10 & F4F5F6F7F8F10 & F10 & F10 & 0 \\
\hline F11 & F5F6F11 & F9F11 & F11 & 0 \\
\hline
\end{tabular}

\begin{tabular}{|c|c|c|c|c|}
\hline Variable_Names & Reachability_Set & Antecedents_Set & intersection_Set & Level \\
\hline F4 & F4F5 & F4F7F8F9F10 & F4 & 0 \\
\hline F5 & F5 & F4F5F7F8F9F10F11 & F5 & 1 \\
\hline F7 & F4F5F7F8 & F7F8F9F10 & F7F8 & 0 \\
\hline F8 & F4F5F7F8 & F7F8F9F10 & F7F8 & 0 \\
\hline F9 & F4F5F7F8F9F11 & F9 & F9 & 0 \\
\hline F10 & F4F5F7F8F10 & F10 & F10 & 0 \\
\hline F11 & F5F11 & F9F11 & F11 & 0 \\
\hline
\end{tabular}

\begin{tabular}{|c|c|c|c|c|}
\hline Variable_Names & Reachability_Set & Antecedents_Set & Intersection_Set & Level \\
\hline $\mathrm{F} 4$ & $\mathrm{~F} 4$ & F4F7 F8 F9F10 & $\mathrm{F} 4$ & 1 \\
\hline F7 & F4F7F8 & F7 F8 F9F10 & F7 F8 & 0 \\
\hline$F 8$ & F4F7F8 & F7F8 F9F10 & F7 F8 & 0 \\
\hline F9 & F4 F7 F8 F9 F11 & F9 & F9 & 0 \\
\hline $\mathrm{F} 10$ & F4F7F8F 10 & $\mathrm{~F} 10$ & $\mathrm{~F} 10$ & 0 \\
\hline F11 & F11 & F9F11 & F11 & 1 \\
\hline
\end{tabular}

\begin{tabular}{|c|c|c|c|c|}
\hline Variable_Names & Reachability_Set & Antecedents_Set & Intersection_Set & Level \\
\hline F7 & F7F8 & F7F8F9F10 & F7F8 & 1 \\
\hline F8 & F7F8 & F7F8F9F10 & F7F8 & 1 \\
\hline F9 & F7F8F9 & F9 & F9 & 0 \\
\hline F10 & F7F8F10 & F10 & F10 & 0 \\
\hline
\end{tabular}

\begin{tabular}{|c|c|c|c|c|}
\hline Variable_Names & Reachability_Set & Antecedents_Set & Intersection_Set & Level \\
\hline F9 & F9 & F9 & F9 & 1 \\
\hline F10 & F10 & F10 & F10 & 1 \\
\hline
\end{tabular}

Figure 1. Level partition of each iteration. 


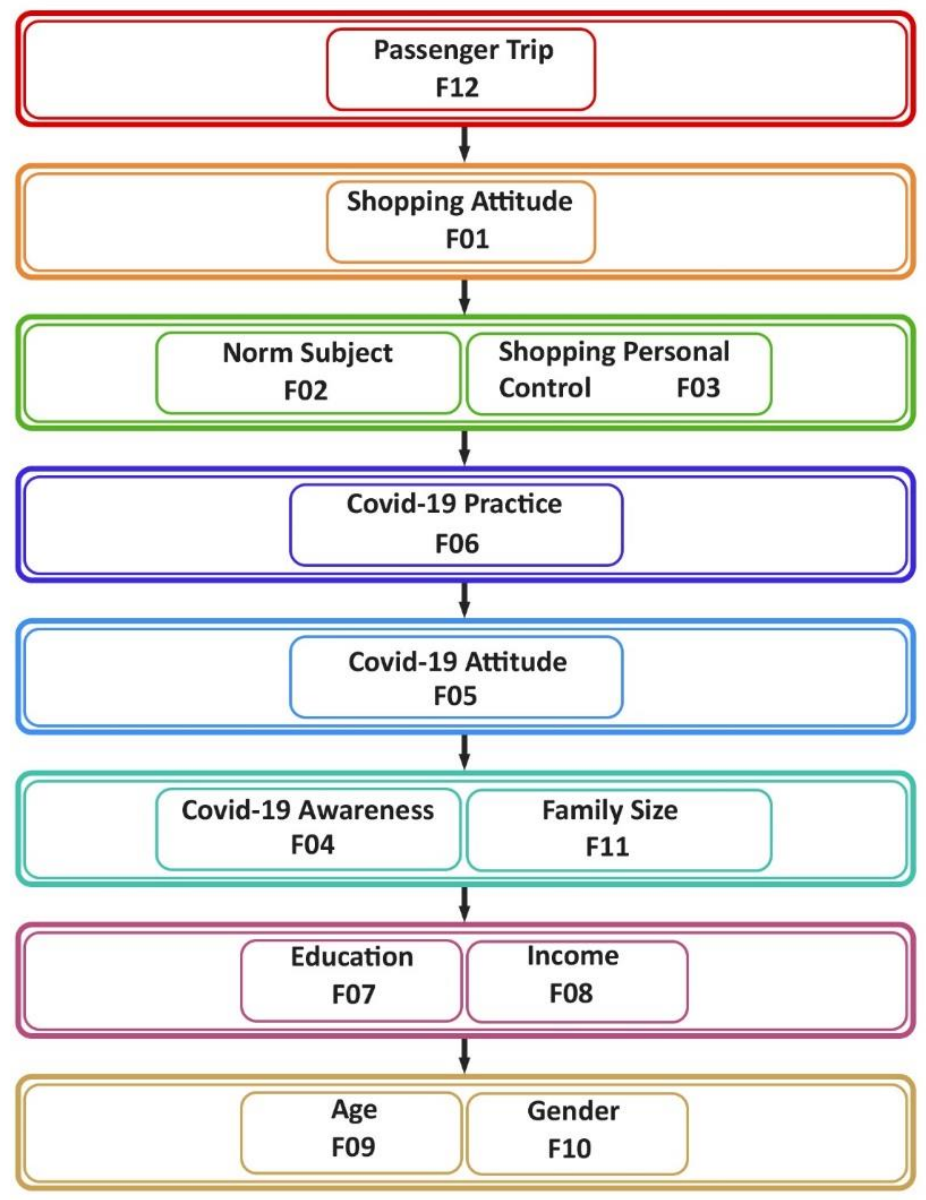

Figure 2. Final output of the ISM.

\subsection{MICMAC Analysis}

MICMAC analysis consists of following elements:

Driver power: The number of elements that element $i$ affects.

Dependence power: The number of elements that affect the element $i$.

In this analysis, the variables are divided into four groups: autonomous, dependent, linked (independent), and independent.

Autonomous factors: Autonomous variables have low dependencies and conductivities. In general, these criteria are separated from the system because they do not have good connections with the system. Changes in these variables do not change the system in a significant way.

Independent factor: Independent variables have strong dependence and poor conductivity. These variables generally have high effectiveness and little impact on the system.

Dependent factors: A dependent variable has low dependence and high conductivity. The characteristics of these variables are high effectiveness and low impact.

Linkage factors: Linkage interface variables have high dependency and conductivity. Therefore, the effectiveness of these criteria is very high, and any change in these variables will cause significant changes in the system.

Figure 3 shows the graphical output of MICMAC analysis. 


\section{MICMAC ANALYSIS}

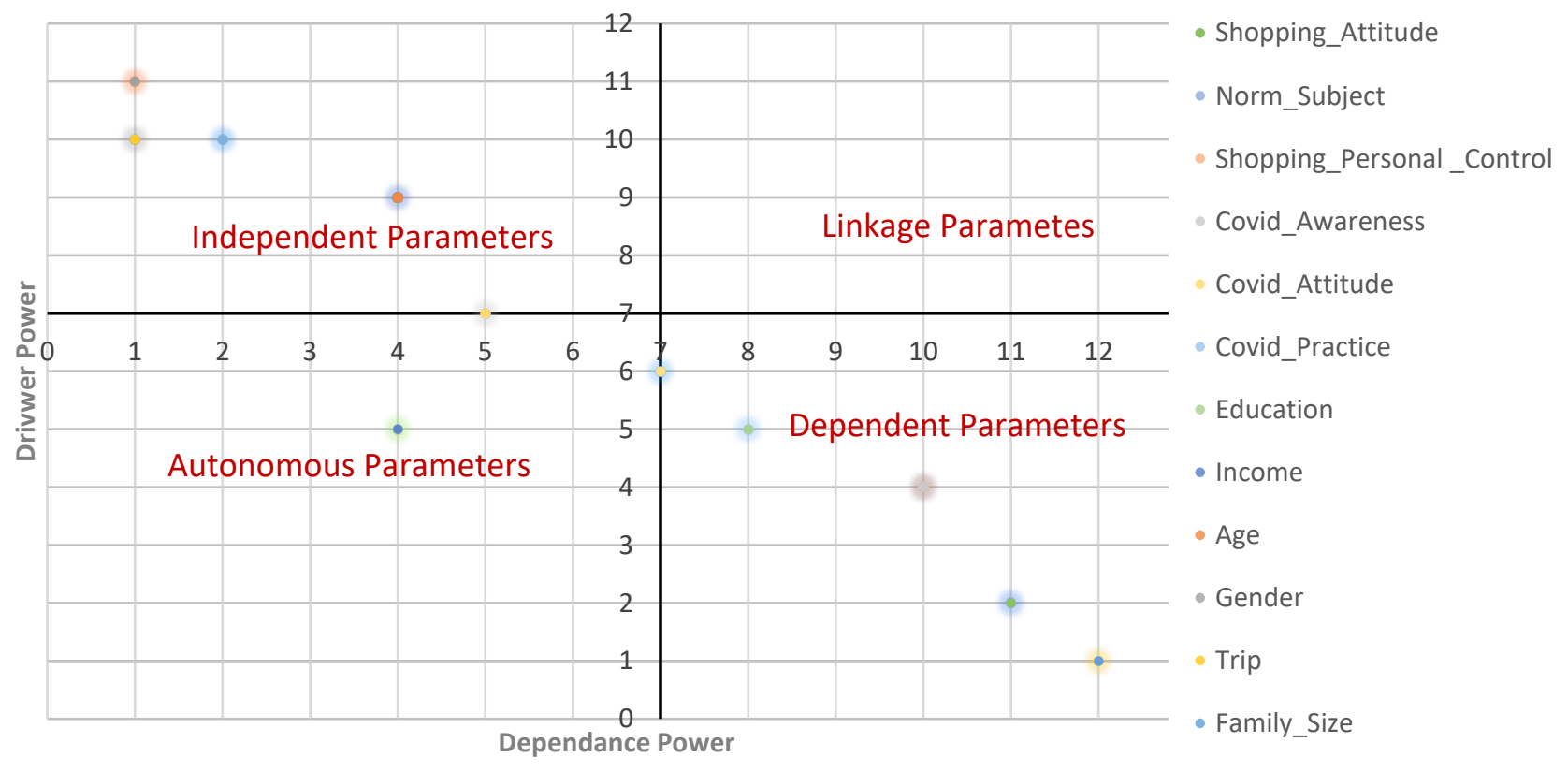

Figure 3. Output of MICMAC analysis.

\subsection{Interpretations and Findings of ISM Modeling}

In Figure 3, the MICMAC analysis explains that the variables of age, gender, income, family size, and COVID-19 awareness are independent variables and have directly/indirectly impacted other characteristics and have the most significant impact on the system. They are located in the northwest quadrant of the chart, and changes to them can alter the output and results. Southeast of the chart is the dependent variables. They include attitudes toward COVID-19, COVID-19 practices, personal shopping control, attitudes toward online shopping, and attitudes toward urban travel. These variables have low driving power and high dependency, are controlled by independent variables, and tend to be significant variables. These variables are the outputs of the system and are the ones most affected by the input variables. The only variable located in the southeastern part of the chart is education, with weak driving power, and consists of weak dependence power as part of the MICMAC system's autonomous section.

Furthermore, this variable can be an unconnected variable, which other variables can control. As a result, this variable has very little power, so it is out of the system. According to the analysis of the MICMAC method and the high driving power and low dependence of the variables located in northwest quadrant of the chart, for example, it is possible to use the classified programs for different ages and genders to obtain the necessary knowledge to correct behavior toward the COVID-19 pandemic by adopting that it directly affects the attitude and practice of COVID-19 on the one hand and the attitude of the shopping on the other hand and, thus, indirectly affects people's trip. This study shows that since the variables are not placed adjacent to the coordinate diameter, the system is not unstable. Despite this, it has not fully formed a complete L-shape that can be considered stable. Considering that some variables of this study are related to COVID-19 and are inherently temporary, as well as the fact that online shopping is a fairly new phenomenon in Iran, this is both expected and justified. However, this system seems to be stable.

\subsection{IAHP Modeling}

There are various ways to prioritize factors involving pairwise comparisons, also known as the Analytical Hierarchy Process (AHP). The AHP seeks to select the most 
appropriate option for a given set of requirements using pairwise comparisons. This technique is also used to assess criteria.

Based on the analysis of the ISM model, the variables are arranged into five levels. The first level represents the goal, and the criteria in other levels affect the number of urban trips. The AHP model allows for only the weight of the related criteria to be considered. Thus, the AHP model is based on a goal-criteria structure, which has been used in the present study. Based on Weber and Fechner's Psychophysical Law, which gives a comparative scale of 1 to 9 (Table 5) and is used to show preference, the questionnaire used in the AHP model of preference allocation was written by the same thirty experts in marketing, planning, transportation, and sociology.

Table 5. Grades and semantics in IAHP.

\begin{tabular}{cc}
\hline Grade & Semantics \\
\hline 1 & Equally Preferred \\
3 & Moderately Preferred \\
5 & Strongly Preferred \\
7 & Very Strongly Preferred \\
9 & Extremely Preferred \\
$2,4,6,8$ & Compromises/Between \\
\hline
\end{tabular}

The compatibility of the AHP model is generally lowered with increasing the number of criteria, and the value is generally greater than 0.1 . An expert becomes confused by a pairwise comparison matrix, which is inevitable when the number of criteria increases even for an experienced expert. Due to this problem, the pairwise comparison matrix of the AHP model does not satisfy the requirement for compatibility, and the results of the model are unreliable. Therefore, the IAHP (Improved AHP) model has been used instead of the AHP model in this study.

In the IAHP model, instead of determining the matrix of pairwise comparisons between criteria that require a large number of questions to complete, it determines only the weight of each criterion, and the matrix of pairwise comparisons $A=\left(a_{i j}\right)_{n \times n}$ is generated using the following criteria.

1. Assume $\left\{F_{i}\right\}_{i=1,2, \ldots, n}$ is a set of factors affecting decision $A$, where $\mathrm{n}$ is the number of factors.

2. Order the factors $F_{i}$ according to their importance using a discrete scoring scale from 1 to 9 , which will lead to a set of scores $\left\{f_{i}\right\}_{i=1,2, \ldots, n}$.

3. Generate the $\mathrm{CM}$ according to the $F_{i}$ as their importance:

a. If $f_{i} \geq f_{j}$ the matrix element $a_{i j}=\max \left(f_{i}-f_{j}, 1\right)$.

b. If $f_{i}<f_{j}$ the matrix element $a_{i j}=\frac{1}{\left(f_{j}-f_{i}\right)}$.

Experts determined different values for the weighting of the criteria that were, according to the background literature on the geometric mean, used in this study to determine the values of the matrix of pairwise comparisons. Based on the merged pairwise comparison matrix, the consistency index (CI), Average Consistency Random Index (RI) (Table 6), the values of the weighted criteria were normalized (Table 7), and consistency ratio (CR) values were calculated, which should be less than 0.1 . 
Table 6. Values of random index (RI) based on order of matrix.

\begin{tabular}{cc}
\hline Order of Matrix & RI \\
\hline 1 & 0 \\
2 & 0 \\
3 & 0.52 \\
4 & 0.89 \\
5 & 0.12 \\
6 & 1.26 \\
7 & 1.36 \\
8 & 1.41 \\
9 & 1.46 \\
10 & 1.49 \\
11 & 1.52 \\
12 & 1.54 \\
13 & 1.56 \\
14 & 1.58 \\
15 & 1.59 \\
\hline
\end{tabular}

Table 7. Normalized pairwise comparison matrix.

\begin{tabular}{|c|c|c|c|c|c|c|c|c|c|c|c|c|}
\hline Normalize & $a_{1}$ & $a_{2}$ & $a_{3}$ & $a_{4}$ & $a_{5}$ & $a_{6}$ & $a_{7}$ & $a_{8}$ & $a_{9}$ & $a_{10}$ & $a_{11}$ & Weight \\
\hline$a_{1}$ & 0.026 & 0.030 & 0.024 & 0.023 & 0.023 & 0.025 & 0.025 & 0.026 & 0.030 & 0.027 & 0.024 & 0.026 \\
\hline$a_{2}$ & 0.030 & 0.035 & 0.040 & 0.035 & 0.033 & 0.034 & 0.034 & 0.034 & 0.037 & 0.035 & 0.033 & 0.034 \\
\hline$a_{3}$ & 0.043 & 0.035 & 0.040 & 0.044 & 0.038 & 0.045 & 0.040 & 0.039 & 0.04 & 0.039 & 0.038 & 0.04 \\
\hline$a_{4}$ & 0.095 & 0.082 & 0.075 & 0.082 & 0.062 & 0.074 & 0.103 & 0.100 & 0.071 & 0.080 & 0.090 & 0.083 \\
\hline$a_{5}$ & 0.061 & 0.057 & 0.057 & 0.072 & 0.054 & 0.045 & 0.058 & 0.052 & 0.050 & 0.050 & 0.058 & 0.056 \\
\hline$a_{6}$ & 0.047 & 0.046 & 0.040 & 0.050 & 0.054 & 0.045 & 0.045 & 0.043 & 0.043 & 0.042 & 0.048 & 0.046 \\
\hline$a_{7}$ & 0.122 & 0.120 & 0.117 & 0.095 & 0.111 & 0.118 & 0.118 & 0.115 & 0.113 & 0.143 & 0.119 & 0.117 \\
\hline$a_{8}$ & 0.134 & 0.135 & 0.135 & 0.109 & 0.138 & 0.139 & 0.135 & 0.132 & 0.129 & 0.143 & 0.129 & 0.132 \\
\hline$a_{9}$ & 0.171 & 0.186 & 0.195 & 0.228 & 0.213 & 0.203 & 0.205 & 0.201 & 0.196 & 0.164 & 0.212 & 0.198 \\
\hline$a_{10}$ & 0.156 & 0.165 & 0.168 & 0.169 & 0.178 & 0.175 & 0.135 & 0.152 & 0.196 & 0.164 & 0.148 & 0.164 \\
\hline$a_{11}$ & 0.114 & 0.111 & 0.108 & 0.095 & 0.096 & 0.097 & 0.103 & 0.106 & 0.096 & 0.114 & 0.103 & 0.104 \\
\hline
\end{tabular}

Note: $\mathrm{CI}=0.047, \mathrm{RI}=1.51, \mathrm{CR}=0.0031 \leq 0.1$.

\subsection{Interpretations and Findings of IAHP Modeling}

Table 7 illustrates that the eleven factors mentioned earlier affect the ISM model's output, urban travel. Based on the calculation of the weight values of each of the criteria and the fact that the values of CI (consistency index), RI (average consistency random index), and CR (consistency ratio) are all less than 0.1 , it is clear that all factors affect urban travel. The findings of this section and Figure 4 show that factors related to demographics had the greatest impact on urban travel, followed by COVID-19-related factors. After the previously mentioned factors, online shopping factors (attitude, control, and norm subject) impact urban travel.

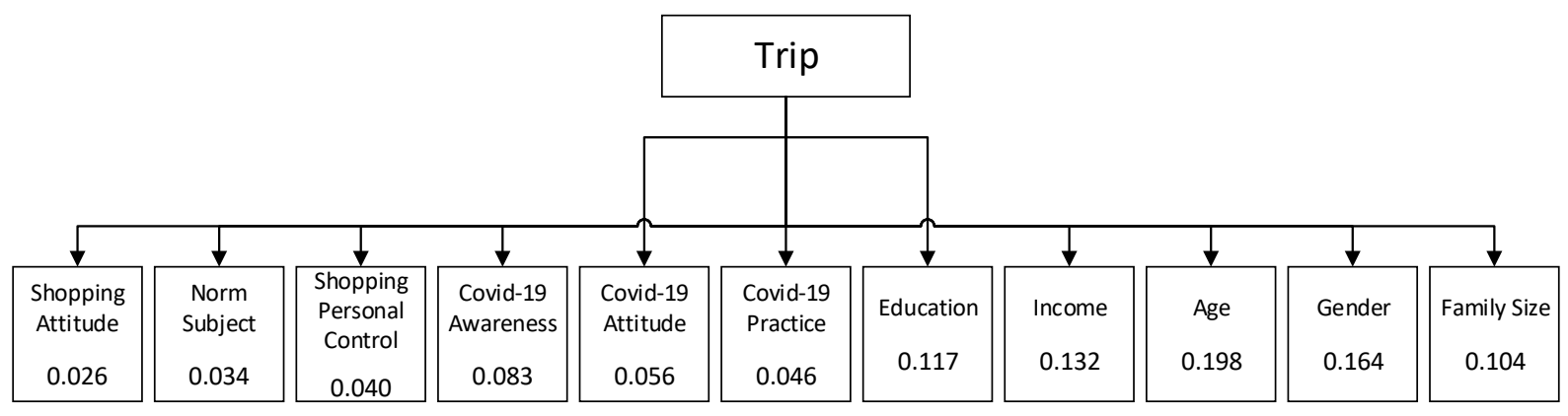

Figure 4. Weight of the factors on urban travel. 


\section{Conclusions}

This study presented four basic categories of online shopping, the COVID-19 pandemic approach, demographic characteristics, and urban travel in the form of an interpretive structural model. The highest level of this model is urban travel. This variable is the most affected by the lower-order variables. It seems evident that due to quarantine restrictions and the need for social distance, people should avoid traveling within the city. Compliance with pandemic protocols is not the only factor that has resulted in reduced urban traffic. In fact, the expansion of online shopping itself is an influential factor in people's urban travel [32].

On the one hand, the factor of buying items needed by households affects urban traffic, and on the other hand, it is affected by COVID-19 itself. According to UNCTAD 2020, the COVID-19 outbreak has affected online shopping, and people are more likely to shop online to maintain social distancing [43]. In this study, the results indicate that online shopping and the social distancing restrictions are directly related to urban travel, while COVID-19 factors are directly associated with online shopping.

Throughout the study results, it was demonstrated that demographic characteristics are among the most fundamental characteristics. In other words, age and gender are the two most significant factors affecting other issues. It is stated in the literature that the gender of individuals influences their attitude response toward COVID-19. According to the literature in this field, gender plays a role in how individuals react to COVID-19 [44], and studies show that gender influences people's attitudes toward online shopping. This factor is an essential predictor for online shopping [45]. Additionally, age is another factor that can determine the community that buys online due to the generation gap [46], which the higher penetration of the internet can explain in the younger generation. In contrast, studies show that age differences lead to a different perception of COVID-19's risks, which can be used to predict protective behavior [47].

Income and education were significantly greater than age and gender, implying that age and gender impacted these two variables. Gender-based income and education effects are well known concerning the issue of gender gaps and discrimination. On the other hand, the effect of age on income and education is also apparent. However, these two variables should be regarded as the essential variables that contribute to the performance of online commerce and COVID-19 in particular. Possibly, income differences affect selfrestriction behavior and elicit different reactions to COVID-19 [45]; also, a level of trust in online shopping can be affected by this factor [48]. Another essential variable is the level of education.

On the one hand, the differences in education facilitate access to new data and analysis on COVID-19, and on the other hand, education can influence the online shopping approach. It seems different educational backgrounds may have different needs and strategies to online shopping [49]. Besides, the number of households may affect the approach to online shopping. Online shopping literature has considered the impact of this factor, revealing its importance [50]. It can be inferred that household size can provide information about the desire of people to shop online.

On the whole, online shopping affects urban trips, and the increase in online shopping during the epidemic has led to a more significant impact. Not only can these findings be used to reduce urban trips in postpandemic times, but they will also decrease urban travel in the future, when people's attitudes toward crisis will remain positive to reduce urban trips so that everyone can do so with no problems obtaining essentials.

Based on the proposed interpretive structural model, it can be concluded that urban travel has been influenced by online shopping and quarantine restrictions. The fact that online shopping soared during the pandemic has led to a double effect. These issues are influenced by several factors, including age, gender, education, income, and household size. Since it is essential to reduce urban traffic from an environmental and psychological perspective and since online shopping is becoming more popular, wholesalers and retailers should take advantage of this experience and keep their new online customers. 


\section{Limitations and Future Research}

The implementation of this research has not faced any particular limitations, and according to the research method, it has been able to achieve its goal, but in the extension of this research, its geographical limits should be considered because cultural and legal issues in each country during the pandemic can affect the relationship between factors. However, this study has shown how factors affect online shopping and the number of urban trips during the pandemic; therefore, the durability of this study in the postpandemic control period can be the subject of research to determine whether the relationship Will these factors be the same under normal circumstances or not?

Author Contributions: Conceptualization, M.G. and A.A.; methodology, M.G. and S.G.; software, M.G. and A.R.; validation, S.G.; formal analysis, M.G. and A.A.; data curation, A.R.; writing-original draft preparation, M.G. and A.A.; writing-review and editing, A.A.; supervision, H.Y. All authors have read and agreed to the published version of the manuscript.

Funding: This research received no external funding.

Data Availability Statement: No public data available.

Conflicts of Interest: The authors declare no conflict of interest.

\section{References}

1. Oum, T.H.; Wang, K. Socially Optimal Lockdown and Travel Restrictions for Fighting Communicable Virus Including COVID-19. Transp. Policy 2020, 96, 94-100. [CrossRef] [PubMed]

2. Taha, V.A.; Pencarelli, T.; Škerh, V.; Fedorko, R.; Koš, M. The Use of Social Media and Its Impact on Shopping Behavior of Slovak and Italian Consumers during COVID-19 Pandemic. Sustainability 2021, 13, 1710. [CrossRef]

3. Clement, J. COVID-19 Impact on Global Retail e-Commerce Site Traffic 2019-2020. Available online: https:/ / www.statista.com/ statistics/1112595/covid-19-impact-retail-e-commerce-site-traffic-global/ (accessed on 20 July 2021).

4. Rukuni, T.F.; Maziriri, E.T. Data on Corona-Virus Readiness Strategies Influencing Customer Satisfaction and Customer Behavioural Intentions in South African Retail Stores. Data Brief. 2020, 31, 105818. [CrossRef] [PubMed]

5. Untaru, E.-N.; Han, H. Protective Measures against COVID-19 and the Business Strategies of the Retail Enterprises: Differences in Gender, Age, Education, and Income among Shoppers. J. Retail. Consum. Serv. 2021, 60, 102446. [CrossRef]

6. Zhang, J.; Zhao, A.; Ke, Y.; Huo, S.; Ma, Y.; Zhang, Y.; Ren, Z.; Li, Z.; Liu, K. Dietary Behaviors in the Post-Lockdown Period and Its Effects on Dietary Diversity: The Second Stage of a Nutrition Survey in a Longitudinal Chinese Study in the Covid-19 Era. Nutrients 2020, 12, 3269. [CrossRef]

7. Chang, H.H.; Meyerhoefer, C.D. COVID-19 and the Demand for Online Food Shopping Services: Empirical Evidence from Taiwan. Am. J. Agric. Econ. 2020, 103, 448-465. [CrossRef]

8. Gao, X.; Shi, X.; Guo, H.; Liu, Y. To Buy or Not Buy Food Online: The Impact of the COVID-19 Epidemic on the Adoption of e-Commerce in China. PLoS ONE 2020, 15, 1-14. [CrossRef]

9. Grashuis, J.; Skevas, T.; Segovia, M.S. Grocery Shopping Preferences during the COVID-19 Pandemic. Sustainability 2020, $12,5369$. [CrossRef]

10. Donthu, N.; Gustafsson, A. Effects of COVID-19 on Business and Research. J. Bus. Res. 2020, 117, 284-289. [CrossRef]

11. Kirk, C.P.; Rifkin, L.S. I'll Trade You Diamonds for Toilet Paper: Consumer Reacting, Coping and Adapting Behaviors in the COVID-19 Pandemic. J. Bus. Res. 2020, 117, 124-131. [CrossRef]

12. Pantano, E.; Pizzi, G.; Scarpi, D.; Dennis, C. Competing during a Pandemic? Retailers' Ups and Downs during the COVID-19 Outbreak. J. Bus. Res. 2020, 116, 209-213. [CrossRef]

13. Hao, N.; Wang, H.H.; Zhou, Q. The Impact of Online Grocery Shopping on Stockpile Behavior in Covid-19. China Agric. Econ. Rev. 2020, 12, 459-470. [CrossRef]

14. Chen, Y.; Rajabifard, A.; Sabri, S.; Potts, K.E.; Laylavi, F.; Xie, Y.; Zhang, Y. A Discussion of Irrational Stockpiling Behaviour during Crisis. J. Saf. Sci. Resil. 2020, 1, 57-58.

15. Cochran, A.L. Impacts of COVID-19 on Access to Transportation for People with Disabilities. Transp. Res. Interdiscip. Perspect. 2020, 8, 100263. [CrossRef]

16. Laato, S.; Islam, A.K.M.N.; Farooq, A.; Dhir, A. Unusual Purchasing Behavior during the Early Stages of the COVID-19 Pandemic: The Stimulus-Organism-Response Approach. J. Retail. Consum. Serv. 2020, 57, 102224. [CrossRef]

17. Lopes, B.; Bortolon, C.; Jaspal, R. Paranoia, Hallucinations and Compulsive Buying during the Early Phase of the COVID-19 Outbreak in the United Kingdom: A Preliminary Experimental Study. Psychiatry Res. 2020, 293, 113455. [CrossRef]

18. Naeem, M. Do Social Media Platforms Develop Consumer Panic Buying during the Fear of Covid-19 Pandemic. J. Retail. Consum. Serv. 2021, 58, 102226. [CrossRef] 
19. Prentice, C.; Chen, J.; Stantic, B. Timed Intervention in COVID-19 and Panic Buying. J. Retail. Consum. Serv. 2020, 57, 102203. [CrossRef]

20. Islam, T.; Pitafi, A.H.; Arya, V.; Wang, Y.; Akhtar, N.; Mubarik, S.; Xiaobei, L. Panic Buying in the COVID-19 Pandemic: A Multi-Country Examination. J. Retail. Consum. Serv. 2021, 59, 102357. [CrossRef]

21. Sheth, J. Impact of Covid-19 on Consumer Behavior: Will the Old Habits Return or Die? J. Bus. Res. 2020, 117, 280-283. [CrossRef]

22. Lehberger, M.; Kleih, A.K.; Sparke, K. Panic Buying in Times of Coronavirus (COVID-19): Extending the Theory of Planned Behavior to Understand the Stockpiling of Nonperishable Food in Germany. Appetite 2021, 161, 105118. [CrossRef]

23. Chen, Q.; Pan, S. Transport-Related Experiences in China in Response to the Coronavirus (COVID-19). Transp. Res. Interdiscip. Perspect. 2020, 8, 100246. [CrossRef] [PubMed]

24. de Vos, J. The Effect of COVID-19 and Subsequent Social Distancing on Travel Behavior. Transp. Res. Interdiscip. Perspect. 2020, 5, 100121. [CrossRef]

25. Muley, D.; Ghanim, M.S.; Mohammad, A.; Kharbeche, M. Quantifying the Impact of COVID-19 Preventive Measures on Traffic in the State of Qatar. Transp. Policy 2021, 103, 45-59. [CrossRef]

26. Abdullah, M.; Dias, C.; Muley, D.; Shahin, M.D. Exploring the Impacts of COVID-19 on Travel Behavior and Mode Preferences. Transp. Res. Interdiscip. Perspect. 2020, 8, 100255. [CrossRef] [PubMed]

27. Loske, D. The Impact of COVID-19 on Transport Volume and Freight Capacity Dynamics: An Empirical Analysis in German Food Retail Logistics. Transp. Res. Interdiscip. Perspect. 2020, 6, 100165. [CrossRef]

28. Dong, H.; Ma, S.; Jia, N.; Tian, J. Understanding Public Transport Satisfaction in Post COVID-19 Pandemic. Transp. Policy 2021, 101, 81-88. [CrossRef]

29. Hensher, D.A.; Wei, E.; Beck, M.J.; Balbontin, C. The Impact of COVID-19 on Cost Outlays for Car and Public Transport Commuting - The Case of the Greater Sydney Metropolitan Area after Three Months of Restrictions. Transp. Policy 2021, 101, 71-80. [CrossRef]

30. Parady, G.; Taniguchi, A.; Takami, K. Travel Behavior Changes during the COVID-19 Pandemic in Japan: Analyzing the Effects of Risk Perception and Social Influence on Going-out Self-Restriction. Transp. Res. Interdiscip. Perspect. 2020, 7, 100181. [CrossRef]

31. Giglierano, J.; Roldan, M. Effects of Online Shopping on Vehicular Traffic; MTI Report 01-20; Mineta Transportation Institute San José State University: San Jose, CA, USA, 2001.

32. Peng, C. Does E-Commerce Reduce Traffic Congestion? Evidence from Alibaba Single Day Shopping Event Cong Peng; Centre for Economic Performance: London, UK, 2019.

33. Ajzen, I. The Theory of Planned Behavior. Organ. Behav. Hum. Decis. Process. 1991, 50, 179-211. [CrossRef]

34. Chandra, A.K.; Sinha, D.K. Factors Affecting the Online Shopping Behaviour: A Study With Reference To Bhilai Durg. Int. J. Adv. Res. Manag. Soc. Sci. 2013, 2, 160-177.

35. Alahdal, H.; Basingab, F.; Alotaibi, R. An Analytical Study on the Awareness, Attitude and Practice during the COVID-19 Pandemic in Riyadh, Saudi Arabia. J. Infect. Public Health 2020, 13, 1446-1452. [CrossRef]

36. Attri, R.; Dev, N.; Sharma, V. Interpretive Structural Modelling (ISM) Approach: An Overview. Res. J. Manag. Sci. 2013, 2, 3-8.

37. Anand, A.; Bansal, G. Interpretive Structural Modeling for Attributes of Software Quality. J. Adv. Manag. Res. 2017, 14. [CrossRef]

38. Fengwei, L.; Kwang, P.K.; Xiuli, D.; Mingju, Z. Improved AHP Method and Its Application in Risk Identification. J. Constr. Eng. Manag. 2013, 139, 312-320.

39. Lins, S.; Aquino, S. Development and Initial Psychometric Properties of a Panic Buying Scale during COVID-19 Pandemic. Heliyon 2020, 6, e04746. [CrossRef] [PubMed]

40. Passavanti, M.; Argentieri, A.; Barbieri, D.M.; Lou, B.; Wijayaratna, K.; Foroutan Mirhosseini, A.S.; Wang, F.; Naseri, S.; Qamhia, I.; Tangerås, M.; et al. The Psychological Impact of COVID-19 and Restrictive Measures in the World. J. Affect. Disord. 2021, 283, 36-51. [CrossRef] [PubMed]

41. Alaimo, L.S.; Fiore, M.; Galati, A. How the COVID-19 Pandemic Is Changing Online Food Shopping Human Behaviour in Italy. Sustainability 2020, 12, 9594. [CrossRef]

42. Koch, J.; Frommeyer, B.; Schewe, G. Online Shopping Motives during the COVID-19 Pandemic-Lessons from the Crisis. Sustainability 2020, 12, 10247. [CrossRef]

43. UNCTAD COVID-19 Has Changed Online Shopping Forever, Survey Shows. Available online: https://unctad.org/news/covid19-has-changed-online-shopping-forever-survey-shows. (accessed on 17 July 2021).

44. Galasso, V.; Pons, V.; Profeta, P.; Becher, M.; Brouard, S.; Foucault, M. Gender Differences in COVID-19 Attitudes and Behavior: Panel Evidence from Eight Countries. Proc. Natl. Acad. Sci. USA 2020, 117, 27285-27291. [CrossRef]

45. Lin, X.; Featherman, M.; Brooks, S.; Hajli, N. Exploring Gender Differences in Online Consumer Purchase Decision Making: An Online Product Presentation Perspective. Inf. Syst. Front. 2019, 21. [CrossRef]

46. Wan, Y.; Nakayama, M.; Sutcliffe, N. The Impact of Age and Shopping Experiences on the Classification of Search, Experience, and Credence Goods in Online Shopping. Inf. Syst. E-Bus. Manag. 2012, 10, 135-148. [CrossRef]

47. Pasion, R.; Paiva, T.O.; Fernandes, C.; Barbosa, F. The AGE Effect on Protective Behaviors During the COVID-19 Outbreak: Sociodemographic, Perceptions and Psychological Accounts. Front. Psychol. 2020, 11, 561785. [CrossRef] [PubMed]

48. Punj, G. Effect of Consumer Beliefs on Online Purchase Behavior: The Influence of Demographic Characteristics and Consumption Values. J. Interact. Mark. 2011, 25, 134-144. [CrossRef] 
49. Mityko, D.S.V. Consumers' Education Level Impact on the Perception of the Search Experience Credence Products-Empirical Evidence. J. Internet E-Bus. Stud. 2012, 2012, 617588. [CrossRef]

50. Richa, D. Impact of Demograpgic Factors of Consumers on Online Shopping Behaviour: A Study of Consumers in India. Int. J. Eng. Manag. Sci. 2012, 3, 43-52. 